\title{
Erratum
}

\section{Anticancer drug development: preclinical screening, clinical trials and approval}

\section{BA Teicher, DL Selwood and PA Andrews}

British Journal of Cancer (2004) 9I, 1977. doi:10.1038/sj.bjc.6602286 www.bjcancer.com (c) 2004 Cancer Research UK

Correction to: British Journal of Cancer (2004) 91, 1000. doi:10.1038/sj.bjc.6602070

Due to an error, the ISBN number of the book reviewed above was given incorrectly. The correct number is shown below:

ISBN - 1588292282 . 